\title{
CONTROL CONSTITUCIONAL ABSTRACTO, CONCRETO, MAXIMALISTA Y MINIMALISTA.*
}

\section{Fabio Enrique Pulido Ortiz**}

Fecha de Recepción: 16 de marzo de 2011

Fecha de Aceptación: 13 de abril de 2011

Artículo resultado de Investigación

\begin{abstract}
Resumen
La Corte Constitucional colombiana está encargada de asegurar la supremacía e integridad de la Constitución a través de dos mecanismos: el juico de constitucionalidad de normas con fuera de ley y actos legislativos y la revisión de las decisiones judiciales relacionadas con la acción de tutela. Comúnmente se explica que, en cuanto al primer mecanismo, la Corte realiza un control abstracto de constitucionalidad, mientras que en el segundo, un control concreto. Tal distinción es deficiente si los criterios relevantes para hacerlo son la naturaleza normativa del primero y la existencia de un caso para el segundo. Las deficiencias en la tipificación de las funciones de control constitucional impactan en la concepción del precedente judicial pues deja sin fundamento la tesis según la cual los precedentes de la Corte en las sentencias de control abstracto deben ser de tipo maximalista mientras que las de control concreto de tipo minimalista.
\end{abstract}

\section{Palabras Clave}

Derecho constitucional, Teoría legal, sentencia judicial, minimalismo, maximalismo

\section{ABSTRACT, CONCRET, MAXIMALIST AND MINIMALIST JUDICIAL REVIEW}

\begin{abstract}
The Colombian Constitutional Court is charge of reviewing the integrity and supremacy of the constitution through two institutional powers: to review laws and constitutional reform acts and to review the judgment related to the constitutional actions (tutelage of rights). Traditionally, the scholars define the first institutional power like an abstract judicial review and the second like a concrete judicial review. This definition is wrong if the relevant criteria are the normative nature in the abstract review and the existence of a case in the concrete review. The deficiencies in typifications of the constitutional control impact on conceptions of judicial precedent and leave without support the thesis according to which the judicial precedents in the abstract review judgment should be maximalist and the concrete review judgment should be minimalist.
\end{abstract}

Artículo desarrollado dentro proyecto de investigación Doctrina Judicial Vincualnet de la Corte Constitucional”, financiado por la Universidad Católica de Colombia.

** Abogado Universidad Católica de Colombia, Magíster en Derecho por la Universidad de Palermo. Profesor titular de Derecho Constitucional e investigador del Centro de Investigaciones de la Facultad de Derecho de la Universidad Católica de Colombia, Director del semillero "Observatorio de Justicia Constitucional" de la Universidad Católica de Colombia e investigador principal en "Doctrina Judicial de la Corte Constitucional”. fepulido@ucatolica.edu.co 


\title{
Keywords
}

Constitucional law, legal theory, legal decisions, minimalism, maximalism.

\section{CONTROLE CONSTITUCIONAL ABSTRATO, CONCRETO, MAXIMALISTA E MINIMALISTA}

\begin{abstract}
RESUMO
ACorte Constitucional colombiana estaencarregadade garantir asupremacia eintegridade da Constituição através de dois mecanismos: o julgamento de constitucionalidade de normas fora de lei e atos legislativos, e a revisão das decisões judiciais relacionadas com a ação de tutela. Quanto ao primeiro mecanismo, normalmente é explicado que a Corte faz um controle abstrato de constitucionalidade, enquanto que o segundo faz um controle concreto. Essa distinção é deficiente se os critérios relevantes para o controle são de natureza normativa, no primeiro, e a existência de um caso, no segundo.
\end{abstract}

As deficiências na tipificação das funções de controle constitucional causam impacto na concepção do precedente judicial, pois deixa sem fundamento a tese segundo a qual os precedentes da Corte nas sentenças de controle abstrato devem ser de tipo maximalista, enquanto que as de controle concreto, de tipo minimalista.

\section{Palavras-chave}

Direito Constitucional, teoria legal, sentença judicial, minimalismo, maximalismo.

\section{INTRODUCCIÓN}

La Constitución Política de Colombia de 1991 confió a la Corte Constitucional la guarda y la supremacía de la Constitución lo cual cumple a través de dos tipos de decisiones: sentencias de constitucionalidad (en adelante sentencias tipo "C") y de tutela (en adelante sentencias tipo "T"). Mediante las primeras la Corte Constitucional realiza el de constitucionalidad de normas con fuerza de ley y actos legislativos; y mediante las segundas revisa las decisiones judiciales relacionadas con la acción de tutela (en adelante AT) para la protección de los derechos fundamentales de las personas. Mediante estas decisiones la Corte Constitucional cuenta con instrumentos de poder que deben ser atentamente estudiados y evaluados. En este sentido venimos estudiando diferentes aspectos del poder normativo de la Corte Constitucional tales como la incidencia de los cambios en la composición de la Corte Constitucional en el desarrollo jurisprudencial (PULIDO ORTIZ: 2009a y 2010a), la jurisprudencia constitucional como marco normativo del trámite legislativo (RINCÓN \& SUAREZ: 2010), y cuestiones metodológicas en torno a la identificación e interpretación de precedentes constitucionales (PULIDO ORTIZ: 2008).

En el estudio que se presenta en este artículo se tomaron como premisas las siguientes conclusiones generadas en las investigaciones: (1) la identificación del precedente constitucional en sentencias $\mathrm{T}$ se dificulta cuando la Corte Constitucional no precisa la situación de vulneración sino que se limita a nombrar referentes constitucionales o situaciones genéricas sin precisar el problema constitucional específico. De manera similar, en las sentencias $C$ la identificación del precedente se dificulta cuando la Corte Constitucional no define con claridad la interpretación de la ley que resulta efectivamente enjuiciada. (2) En las sentencias tipo C, la Corte Constitucional suele identificar como precedente una norma de carácter general 
desligada de las normas o procedimiento legislativo analizado en las sentencias precedentes. (3) En los casos de tutela se tiende a diferenciar con mayor claridad entre la regla aplicable al caso de la regla efectivamente aplicada. (4) Las sentencias de constitucionalidad no están desprovistas de análisis de hechos, principalmente en aquellas sentencias que revisan la constitucionalidad del trámite legislativo, en donde es indispensable identificar claramente la situación fáctica (el hecho u omisión del legislador) que debe ser contrastada con la Constitución. (PULIDO ORTIZ: 2009a y 2011).

En este estudio se defiende que tales premisas desestabilizan la tradicional distinción entre control constitucional abstracto y concertó y los criterios para la identificación y determinación de la fuera vinculante de los precedentes constitucionales. Para ello (i) se explica que tipo de conflicto normativo es el control constitucional, (ii) se define que situación normativa se genera en las sentencias de la Corte Constitucional, en seguida (iii) se presentan las teorías maximalistas y minimalistas en la identificación de precedentes constitucionales, para por ultimo (iv) presentar las conclusiones.

\section{CONTROL CONSTITUCIONAL EN COLOMBIA Y DEFICIENCIAS EN SU CARACTERIZACIÓN}

Caracterizar la Jurisdicción Constitucional colombiana no es tarea sencilla. De acuerdo con un criterio funcional, ella comprende no solamente el control de constitucionalidad de las leyes, sino toda acción y todo recurso de índole judicial destinados a asegurar la prevalencia de la constitución. De conformidad con este criterio, la Jurisdicción Constitucional tiene mayor alcance que el sistema de control judicial de leyes mediante el cual se verifica el respeto de las leyes de la constitución, y comprende todo mecanismo judicial encargado de defender la constitución y garantizar su vigencia y el respeto de los derechos en ella reconocidos. La Jurisdicción Constitucional, según esta concep- ción, incluye, además de la acción pública de inconstitucionalidad de las leyes, la acción de tutea y otras acciones constitucionales como la acción de cumplimiento, la acción pública de constitucionalidad contra decretos generales del gobierno nacional, las acciones populares, las acciones de grupo, entre otras, cada una de las cuales dispone de diferentes órganos de cierre y procedimientos específicos (así, por ejemplo, en lo referente a acciones populares, el órgano de cierre es la CSJ o el Consejo de Estado, según si el sujeto pasivo de la acción es un particular o es el Estado). Debe tenerse en cuenta que además de las funciones encomendadas específicamente a la Corte Constitucional, la CP dispone en su Art. 4 que "en caso de incompatibilidad de la constitución y la ley, se aplicarán las disposiciones constitucionales", por lo cual existe también un control de tipo difuso y concreto encomendado a todos los jueces del país.

En este artículo limitamos el estudio a las acciones y procesos mediante los cuales se lleva a cabo el juicio de exequibilidad de leyes y la protección de los derechos fundamentales confiados por el artículo 241 de la Constitución Política de Colombia a la Corte Constitucional Colombiana de la siguiente manera: (1) control de constitucionalidad de normas con rango de ley y actos reformatorios de la constitución y (2) revisión de las decisiones judiciales relacionadas con la AT de los derechos fundamentales. (PULIDO ORTIZ: 2009b). Comúnmente se explica que, en cuanto al primer mecanismo, la Corte realiza un control abstracto de constitucionalidad, mientras que en el segundo, un control concreto de constitucionalidad.

La distinción entre control abstracto y concreto de constitucionalidad fue desarrollada por Kelsen. Para este autor en el control constitucional concreto se faculta a los jueces para analizar la constitucionalidad de las normas que deben aplicar en el caso concreto, y para negarse a aplicarla si encuentran son inconstitucionales. Por su parte, en el control abstracto de constitucionalidad se faculta a los jueces para que definan la inconstitucionalidad de las normas 
desligándose de los casos concretos (KELSEN: 1942). La diferencia entre uno y otro tipo de control constitucional es, según lo dicho, que en el control concreto se define si determinado en caso se está desconocido una norma constitucional, mientras que en el abstracto se realiza una constatación de compatibilidad lógica entre una norma infra-constitucional y una norma constitucional (QUINCHE: 2008).

Caracterizar las sentencias tipo "C" de la corte constitucional como un juicio de compatibilidad lógica entre dos normas y abstracto en el sentido de que no se juzgan casos resulta deficiente por dos razones fundamentales: (i) no es cierto que el control constitucional implique un análisis estrictamente normativo de compatibilidad lógica y (ii) en las sentencias tipo "c" también se juzgan casos. El argumento que se defiende es que si el criterio que se usa para clasificar el control constitucional es el normativo, tanto las sentencias "c" como las "t" son juicios de compatibilidad normativa.

Es un lugar común justificar el control constitucional judicial como correlato necesario de la existencia de una Constitución como fuente de validez del sistema normativo. Esta idea, que en sus orígenes tenía un alcance estrictamente e formal ${ }^{1}$, ha desarrollado con el tiempo un alcance sustantivo o material ${ }^{2}$. Sin embargo, el

1 El control constitucional como juicio lógico (lógica Marshall en términos de C. Nino) formula que en el caso de un conflicto normativo entre la constitución y la ley, y teniendo en cuenta que existen solo dos posibilidades: (i) aplicar la constitución dejando de lado la ley o (ii) aplicar la ley a pesar de la constitución debe aplicar la constitución, el juez debe preferir la constitución sobre la ley, los jueces deben preferir la constitución sobre la ley. (C. Nino, 1992).

2 La teoría de la constitución como norma jurídica implica que los contenidos de las normas constitucionales $-y$ por ese solo hecho- deben ser exigidos judicialmente y que, por el contrario, la inexistencia de un control judicial de la constitución deviene en la inexistencia material de la misma. Véase, entre muchos otros, E. García de Enterría (1983) y Manuel Quinche (2008). La Corte Constitucional colombiana ha recurrido en innumerables ocasiones a este argumento, a manera de ejemplo véase la sentencia T-406-1992 (Magistrado Ponente Angarita Barón) una de las primeras en hacerlo. control constitucional no puede ser entendió, ni justificado, como una operación lógica de compatibilidad entre dos normas toda vez que, como lo demostró Carlos Nino, (1992) dicha teoría no puede explicar cómo pueden leyes que objetivamente contradicen la Constitución ser validas, bien sea porque la ley no fue demandada ante la justicia o que siendo planteada los jueces deciden declárala constitucional (por error o por cuestiones procedimentales) por lo que una ley objetivamente inconstitucional mantiene "incólume su fuerza obligatoria" (p. 675). En otras palabras, el control judicial de la Constitución no es una operación de simple lógica y por lo tanto se requieren argumentos que justifiquen porque los jueces, en nuestro caso la Corte Constitucional, están facultados para invalidar las leyes.

El control constitucional es en su esencia una actividad de naturaleza valorativa, es decir es un acto de naturaleza moral en donde confluyen la libertad y voluntad del intérprete. Para caracterizar desde un punto de vista normativo el control constitucional se debe tener en cuenta los siguientes problemas:

(i) La ambigüedad de la palabra norma. La palabra norma es empleada para definir dos objetos con diferencias muy marcadas: (a) norma como texto legal, es decir enunciados lingüísticos que se encuentran dentro de un documento normativo; por otro lado, (b) el termino norma se emplea para referirse al significado del texto legal -de la norma en el primer sentido (R. Gusatini, 1999). En la primera acepción, norma -como texto normativo- se refiere exclusivamente a aquellos documentos (y cada una de sus partes) que son considerados como fuentes formales de normas jurídicas (e.g constitución, códigos, decretos etc.). Norma, según la segunda de las acepciones, puede ser de carácter conceptual, constitutivo y deóntico. Las normas conceptuales tienen por objeto definir términos legales, las constitutivas determinan quines tienen poderes normativos y las deónticas establecen como jurídicamente obligatorio, prohibido o 
facultativo un caso. La relevancia de dicha distinción radica en que los ordenamientos jurídicos están conformados por normas (en el segundo sentido) y no por textos (normas en el primer sentido). ${ }^{3}$

(ii) El juicio de compatibilidad es acerca de normas (en el segundo sentido) que son resultado de la actividad interpretativa. el juicio de compatibilidad consiste en determinar si existe una contradicción lógica entre normas (no entre textos) de tipo constitutivo o deóntico. Las contradicciones lógicas se generan cuando dos normas se refieren a un mismo caso, pero presentan soluciones jurídicas diferentes e incompatibles entre sí (C. Nino, 1980, C. Alchourrón \& E. Buligyn, 1974, J. Rodríguez, 2002). Sin embargo, el juicio de compatibilidad depende de la interpretación que el juez haga de textos y hechos, es decir que el análisis acerca de la consistencia o contradicción de normas depende fundamentalmente de las operaciones interpretativas de quien tenga a cargo el control constitucional. Las operaciones interpretativas son la serie de actividades que determinan la norma adscrita a un texto normativo. Si bien algunas operaciones interpretativas pueden ser estrictamente cognitivas (por ejemplo describir que normas se pueden adscribir a un texto normativo), la interpretación judicial es esencialmente volitiva implica una decisión acerca de cuál de las normas es la que en definitiva se adscribe al texto normativo: la interpretación judicial no es nunca interpretación cognitiva, "es siempre interpretación-decisión o, como dicen algunos, interpretación operativa" (GUASTINI, 1999, p. 204).

En virtud de lo anterior, si se pretende conceptualizar el control constitucional desde un punto de vista estrictamente normativo, se

3 Sobre las distintas tipologías normativas véase: $\mathrm{M}$. Atienza y J. Manero (1996), Josep Aguilo (2000), C. Alchourron y E. Bulygin (1974), J. Rodríguez (2002) y C. Massini (2003). debe tener en cuenta que no existen diferencias relevantes entre el control constitucional realizado en las sentencias "c" y " $\mathrm{t}$ ". Es decir, tanto el juicio de constitucionalidad de leyes y actos reformatorios de la Constitución como la revisión del las decisiones judiciales en procesos de AT pueden ser estudiados como un juicio de naturaleza normativa. Es así como un proceso de tutela se puede describir como conformado por los siguientes elementos: (i) un derecho fundamental (como norma), (ii) la acción u omisión de una autoridad pública y (i) el resultado del juicio dependerá de la compatibilidad de (i) y (iii).

Si no es el carácter normativo lo que distingue los tipos de control constitucional, se recurre típicamente a la existencia o inexistencia de un caso como elemento relevante de la categorización. ${ }^{4}$ Sin embargo, como lo han sugerido los hallazgos de las investigaciones citadas en la introducción de este artículo, la distinción no puede apuntar a dicho dato. Para precisar la idea presentaremos la estructura analítica de los asuntos que resuelven las sentencias tipo $\mathrm{C}$ y tipo $\mathrm{T}$ de la Corte Constitucional colombiana.

Según la definición tradicional del control constitucional, éste consiste en el juicio de compatibilidad lógica entre dos normas, una de las cuales es la Constitución. En las sentencias de constitucionalidad se definen dos tipos de asuntos: de procedimiento $\mathrm{y}$ de fondo. En los asuntos de procedimiento se juzga si la expedición de una norma (con fuerza de ley) se llevó a cabo según las formas y procedimientos definidos en las normas constitucionales. En los asuntos de fondo, las sentencias de constitucionalidad juzgan si el contenido de una ley contradice una norma constitucional. Por su parte, en los procesos de tutela se juzga si la actuación (omisión o acción) de una autoridad

4 Debe tenerse en cuenta que las diferencias entre control abstracto y control concreto también está en función de los efectos de las sentencias. Mientras para el control concertó los efectos son inter-partes en el control abstracto son erga omnes. 
viola (contradice) un derecho fundamental (véanse las tablas 1 y 2 ) 5 .

Es cierto que el control constitucional (sea de tutela o de constitucionalidad) puedan ser descritos en términos normativos, pero es falso que en los juicios normativos de las sentencias tipo "C" no exista caso y que en las sentencias tipo "T" no se efectúen abstracciones. Las normas tienen por definición un caso (un conjunto de propiedades, unos hechos) y si las sentencias "C" estudian (enjuician) normas por ende enjuician hechos. Las normas son proposiciones que correlacionan un caso a una solución jurídica. Los casos son un conjunto de propiedades (supuesto de hecho) mientras la solución normativa es la prohibición, obligación o facultad relativa al caso (calificación deóntica) ${ }^{6}$. En efecto, las sentencias que estudian vicios de procedimiento revisan la constitucionalidad de las actuaciones surtidas en el trámite de elaboración de la norma, es decir enjuician hechos pasados. En las sentencias que estudian vicios de fondo, los hechos están dados por la ley enjuiciada. Lo anterior se explica en razón a que los casos (como conjunto de propiedades, de hechos jurídicos) pueden ser reales o hipotéticos. Los casos reales se caracterizan por ser del pasado mientras que los hipotéticos por ser del futuro, es decir casos que se espera que pasen (GUASTINI, 2009).

Tabla $1^{*}$. Estructura del control constitucional en las sentencias tipo C

\begin{tabular}{|c|c|c|}
\cline { 2 - 3 } \multicolumn{1}{c|}{} & Asuntos de procedimiento & Asuntos de fondo \\
\hline \multirow{2}{*}{ Juicio } & Norma constitucional & Norma constitucional \\
\cline { 2 - 3 } & Actuación en el trámite legislativo & Norma legal \\
\hline \multicolumn{2}{|c|}{ *tabla de elaboración propia } \\
\hline
\end{tabular}

Tabla 2*. Estructura del control constitucional en las sentencias tipo T

\begin{tabular}{|c|c|}
\hline \multirow{2}{*}{ Juicio } & Derecho fundamental \\
\cline { 2 - 2 } & Acción u omisión de una autoridad \\
\hline
\end{tabular}

Por otra parte, en las sentencias de tutela (como toda sentencia) la Corte Constitucional realiza abstracciones para poder definir el caso que estudia, es decir distingue de la multiplicidad de hechos que conforman el caso real aquellos que considera relevantes para adjudicar el derecho. Recuérdese, por ejemplo, que el carácter indeterminado de los hechos fue una de las mayores preocupaciones para Jerome Frank (1949). Para él la indeterminación del

5 Debe precisarse que además de estos asuntos, la Corte Constitucional, tanto en las sentencias de tutela como en las de constitucionalidad, resuelve problemas de tipo accesorio tales como procedibilidad, inhibiciones, cosa juzgada, entre otros (F. Pulido Ortiz, 2008 y 2010a). derecho resulta prácticamente inevitable como consecuencia de la compleja actividad de establecer los hechos del caso, pues será esta actividad la que en definitiva determina la norma del caso. En otras palabras, si no existen criterios para definir (o limitar) la conformación del caso no habrá forma de determinar el derecho.

De esta manera, el control constitucional desde un punto de vista normativista consiste, en las sentencias tipo $\mathrm{C}$, en el juicio de consistencia entre una(s) norma(s) constitucional y una(s) norma(s) infra-constitucional. Siguiendo esta

6 Véase J. Moreso (1998) y C. Alchourron y E. Buligyn (1974). 
línea, en las sentencias tipo $\mathrm{T}$ el juicio de consistencia entre una norma constitucional (derecho fundamental) y una norma creada por una autoridad pública o privada. Es decir, incluso los juicios de tutela son normativos toda vez que las actuaciones de las autoridades (sean públicas o privadas) adquieren la estructura de norma (calificación jurídica de un caso). Veamos un ejemplo: en la sentencia T-856-2007 se estudió un asunto en el cual una EPS negó la afiliación de un ciudadano como beneficiario de su compañero permanente. Tal asunto puede ser estructurado como norma:

\begin{tabular}{c|c} 
Caso & Solución \\
\hline $\begin{array}{c}\text { Afiliación de un ciudadano } \\
\text { como beneficiario de su } \\
\text { compañero. }\end{array}$ & $\begin{array}{c}\text { No permitido } \\
\text { (prohibido) }\end{array}$
\end{tabular}

La norma entonces quedaría redactada de la siguiente manera: "No está permitido la afiliación de un ciudadano como beneficiario de su compañero permanente". En la sentencia T-856-2007, el asunto constitucional giró en torno a si la norma prohibitiva es compatible con el derecho fundamental. En definitiva, tanto en los asuntos de tutela como en los de constitucionalidad se define a la relación de compatibilidad de dos normas, una de las cuales es la Constitución. En otras palabras, desde un punto de vista normativista toda sentencia de la Corte Constitucional resulta ser un juicio acerca de la compatibilidad de normas derivadas y normas derivadas de leyes o de actos y omisiones de todas autoridades.

Se podría decir, en todo caso, que las diferencias entre los asuntos de tutela y los asuntos de constitucionalidad radican en que, en los primeros, las propiedades del caso son definidas empíricamente en la relación real del ciudadano con la autoridad, mientras que en los segundos, las propiedades del caso son definidas por el legislador. Sin embargo, esta afirmación debe ser matizada según los siguientes argumentos:

(i) En el análisis del control constitucional, efectuado por la Corte, debe prestarse atención al hecho de que la definición de las normas involucradas en el juico es un asunto eminentemente valorativo y manipulable.

(ii) No resulta extraño que del hecho que la Corte Constitucional profiera tanto sentencias de constitucionalidad como de tutela, utilice los elementos de una y de otra indistintamente. Es decir, los casos "t" inciden en como la Corte formula y resuelve los "c" y de las misma manera, las sentencias " $c$ " generan escenarios de litigio para procesos de tutela.

(iii) Esto último impacta en otro criterio de distinción según el cual el control abstracto es de naturaleza preventiva y el concreto de naturaleza remedial. En efecto, el carácter circular de la relación entre las sentencias tipo $\mathrm{C}$ y $\mathrm{T}$ hace que tanto las primeras dependan de la existencia y configuración de casos reales (lo que las definiría como remedial) como que las segundas definan, gracias al valor del precedente, generen mensajes previos de reproche a determinados actos de las autoridades (lo que las definiría como preventivas).

(iv) Los estudios del precedente judicial en el mundo anglosajón han concluido que los poderes normativos de los jueces no están limitados a la interpretación de normas sino que se debe sumar a facultad de determinar los hechos relevantes (materials facts), es decir aquellos hechos efectivamente seleccionados por el juez para resolver el caso. Para un clásico de la literatura jurídica anglosajona como A. Goodhart (1930) lo que un juez defina como hecho relevante es altamente subjetivo y de ello dependerá el nivel de generalidad o concreción del precedente por lo que, concluye dicho autor que es mediante la elección de los hechos relevantes como los jueces efectivamente crean derecho.

(v) En estas circunstancias, ni los textos ni los hechos son un límite infranqueable a la libertad del juez. En otras palabras, 
las normas de las cuales se hace el juicio de constitucionalidad dependen de la interpretación que el juez haga de textos $y$ hechos. Tales hechos y textos no son más que el material que utiliza el juez para componer el juicio de constitucionalidad.

(vi) Si alguien demanda la ley (X) por violar el artículo constitucional (P), el asunto constitucional dependerá de la lectura que el juez haga tanto de $(\mathrm{X})$ como de $(\mathrm{P})$ de la misma manera, si un ciudadano demanda la actuación $Y$ por ser violatoria del derecho fundamental (Z), el asunto de tutela depende de la lectura que haga el juez (Corte) de $\mathrm{Z}$ y de $\mathrm{Y}$. Las propiedades que conforman las variables $(\mathrm{X}),(\mathrm{P}),(\mathrm{Z})$ y $(\mathrm{Y})$ pueden llegar a ser tan variadas que los conflictos constitucionales no pueden ser definidos a priori y dependen de la configuración fenomenológica de la situación (real) del juicio.

Por lo dicho hasta acá, parece defenderse una homogeneización de todos los asuntos constitucionales. Todo lo contrario, la particularidad de los casos que se presentan para juicios constitucionales son tan amplias (y de tan variados matices) que las clasificaciones (como la distinción entre control abstracto y concreto) son por lo menos inútiles. Asimismo, no se está sugiriendo que no exista una forma de concebir la actividad judicial de una forma concreta, sino que de la actividad que realiza la Corte Constitucional (mezcla de asuntos políticos y jurídicos), deviene una confusión del objeto de la política y la justicia en las funciones de la Corte Constitucional.

La idea -de estirpe aristotélica- de separación entre los objetos de la justicia y la política se cofunden en las sentencias de la Corte Constitucional. Según dicha separación a la política le corresponde la consecución del bien común y por ende opera a través de abstracciones plasmadas en normas generales, mientras que la justicia (encomendada a los jueces) le corresponde la determinación del derecho en casos concretos, dar a cada uno lo suyo, según la fórmula del digesto. Dicho postulado de separación de objetos se diluye en las características duales de la jurisdicción constitucional en Colombia ${ }^{7}$. En efecto, se puede observar que los postulados normativos de las sentencias tipo $\mathrm{C}$ resultan concretizado mediante procesos y sentencias de tutela (de la misma manera como se concibió tradicioalemnte la relación entre ley y decisión judicial). Sin embargo, de este fenómeno no se puede concluir sin más que la lógica del control constitucional sea dé tipo de deductivo, en el sentido de que en las sentencias tipo $\mathrm{C}$ se formulan premisas generales que serán aplicadas deductivamente en casos futuros de carácter concreto, pues las decisiones de tutela (concretas) inciden en como la Corte formula y resuelve problemas abstractos. Este problema no puede ser resuelto con el simple argumento de la colaboración armónica de poderes, el cual dado su alto grado de indeterminación requerirá de estudios empíricos de concentración de poder en la Corte Constitucional en relación con otros poderes y en especial con otros órganos de la rama judicial.

\section{LA IDENTIFICACIÓN DE LAS NORMAS ORIGINADAS EN LAS SENTENCIAS DE LA CORTE CONSTITUCIONAL}

Los estudios comparados de sistemas jurídicos occidentales distinguen entre aquellos pertenecientes a la tradición del common law de aquellos pertenecientes a la tradición continental

7 La estructura dualista del poder judicial se caracteriza porque divide la función constitucional encargada al tribunal constitucional de la función ordinaria encargada de aplicar la legislación a casos concretos. La estructura dualista depende de la pureza, es decir que el control constitucional abstracto sea la única competencia del tribunal constitucional, y la autonomía entendida como el grado en que el Tribunal constitucional está desligado de la jurisdicción ordinaria. (Víctor Ferreres Comella, 2005). La Jurisdicción colombiana esta conformada dentro de una estructura dualista impura, en donde una delimitada jurisdicción ordinaria coexiste con una jurisdicción constitucional cuyo órgano de cierre es la Corte Constitucional. Es impura dado que la jurisdicción ordinaria está vinculada a la constitucional mediante la acción de tutela para la protección de los derechos fundamentales y se establece a la Corte Constitucional como órgano de cierre en dicha materia. (Fabio Pulido Ortiz, 2009b) 
(tradición romano-canónica, derecho continental o civil law). Según la visión tradicional, la diferencia fundamental entre dichos sistemas es el origen pragmático (casuista) del primero y racionalista del segundo. En virtud de esta concepción, la fuente normativa dominante para el sistema pragmático es la jurisprudencia mientras que para el sistema racionalista la ley y más específicamente los códigos (MERRYMAN, 1989). De la perfecta separación conceptual entre dichos sistemas jurídicos no queda sino el ideal. En realidad, los sistemas jurídicos de cada una de las mencionadas tradiciones han tomado préstamos de las otras. En el common law, sin desconocer el rol protagónico del derecho jurisprudencial, se reconoce que el derecho legislado ha adquirido un lugar protagónico en el sistema de fuentes (KALIŠE, 2008 ; WALDRON, 1999). En lo que tiene que ver con los sistemas jurídicos de tradición continental, el fenómeno que mejor ejemplifica esta situación es el creciente valor de los precedentes judiciales. ${ }^{8}$

La sentencia judicial como acto normativo complejo es un entramado de normas -de distintos tipos- argumentos jurídicos y argumentos fácticos. En efecto en una sentencia podemos encontrar normas como texto, normas conceptuales, constitutivas y deónticas. Debe tenerse en cuenta que, por tanto, las sentencias (como texto y acto normativo) son por su propia naturaleza fuentes de normas jurídicas sin importar el sistema de fuentes a que pertenezcan. ${ }^{9} \mathrm{El}$ problema del derecho jurisprudencial (de las normas jurídicas de origen judicial) en países de tradición continental -como Colombia- radica en determinar o interpretar tales normas y su "grado" de obligatoriedad para casos futuros. En otras palabras, son dos las aristas de la problemática de las normas de origen judicial: (i) las

8 Véase, por ejemplo, los estudios de N. MacCormick y R. Summeres (1997), D. López (2006); V. Fon y F. y Parisi (2006); ; S. Legarre y J. Rivera (2006); y E. Sodero (2004)

9 Para un estudio analítico acerca del carácter inevitablemente normativo de las sentencias judiciales véase $G$. Carrio (1978). operaciones interpretativas para la identificación o determinación de la norma y (ii) la definición de su obligatoriedad.

En lo que tiene que ver con las operaciones interpretativas para la identificación de normas en los textos de sentencias, existen por lo menos los siguientes problemas: (a) en dichos textos se entremezclan normas conceptuales, normas deónticas e incluso normas constitutivas, (b) en las sentencias, además, se confunden normas generales y normas individuales ${ }^{10}$; y (c) no existe claridad acerca del momento generador de la norma. Así, por ejemplo, se discute si para la existencia (ni siquiera la obligatoriedad) de los precedentes judiciales se requiere de una sola sentencia o de varias que lo reiteren.

Se debe precisar que la identificación de las normas judiciales ${ }^{11}$ es conceptualmente distinguible de su obligatoriedad. En efecto, se puede identificar una norma y concluir que la misma no es obligatoria, es decir que no existe la "obligación política" de seguirla. Típicamente, existen dos formas para el reconocimiento de la obligatoriedad de las normas judiciales: de hecho y formal. Para lo primero, los tribunales y jueces siguen los precedentes aun cuando no existe una norma que los obligue a ella. Por el contrario, la obligatoriedad formal se refiere a que se ha reconocido (o creado) una norma jurídica que exige el seguimiento de precedentes (SODERO: 2004). Por su puesto que la identificación de la norma judicial (del precedente) define el alcance de la vinculatoriedad hacia el mismo. Así, como veremos, si se recurre a una teoría maximalista del precedente judicial según la cual norma judicial no debe regir estrictamente los hechos resueltos sino que debe ser descrita de manera que se elaboren categorías abstractas y sin limitarse al caso efectivamente resuelto, la

10 Las normas generales son aquellas que definen el caso y la solución de forma abstracta e hipoteca, mientras que las normas individuales son aquellas que definen el caso y la solución de forma concreta.

11 En este articulo empelamos indistintamente las expresiones norma judicial o precedente judicial. 
obligación de seguir el precedente se parecerá a la obligación de seguir una ley. En el mismo sentido, por ejemplo, F. Schauer (2004) ha defendió una concepción maximalista del precedente judicial fundamentándose entre otras cosas en el valor de la seguridad jurídica.

En el derecho anglosajón, la identificación del precedente se refiere a la definición de si determinado argumento es ratio decidendi y si los hechos de los casos son similares en aspectos relevantes. Los jueces están facultados para identificar las circunstancias relevantes del caso para definir si es vinculante o no. La problemática en las distinciones radica en la dificultad de precisar cuáles son los hechos relevantes y cuáles no lo son. Además, la distinción de un precedente, esto es la decisión de aplicarlo o no, está esencialmente condicionada por la opinión que el juez tenga respecto de si existen buenas razones para distinguirlo (ITURRALDE: 1995). Cueto Rúa asegura que la identificación de los hechos relevantes "no obedece a principios lógico-formales, pero se funda en los sentidos inmanentes de justicia que presenta cada caso sometido a consideración de un juez" (1997: 152). En el mismo sentido, Lucke (1989) remarca que los jueces tienen una gran discreción en la manera en que aplican el precedente, y que están dispuestos a distinguir incluso el precedente más similar si consideran que tiende a un resultado no deseado. Esto ha llevado a algunos autores a negar que los precedentes obliguen a los jueces de una manera significativa toda vez que la posibilidad de distinguir modificar el precedente, es completamente manipulable como herramienta argumentativa y retórica (KENNEDY: 1999).

Las ampliaciones y reducciones en la identificación de hechos relevantes tienen una relación directa con la amplitud o restricción de la ratio decidendi. En este contexto, se ha planteado la definición del precedente constitucional entre maximalistas y minimalistas: para los primeros el precedente constitucional debe tener la potencialidad de abarcar hechos que no hacen parte de los hechos relevantes del caso y por tanto resuelven problemas políticos o jurídicos de una forma general. Para los minimalistas, por el contrario, el precedente no debe hablar más allá de lo estrictamente necesario para justificar la respuesta y por tanto en la identificación de aquel el intérprete debe limitarse a la determinación de los hechos de caso juzgado (SUNSTEIN: 2001). En otras palabras para los maximalistas las propiedades del caso que conforman la ratio decidendi deben incorporar situaciones más allá de los hechos relevantes de la sentencia, mientras que para los minimalistas las propiedades del caso que conforma la ratio decidendi se reduce a los hechos relevantes de la sentencia. Asimismo, para el maximalismo la ratio decidendi de una sentencia estará conformada por fundamentos mucho más ambiciosos y abarcativos que los necesarios para decidir el problema planteado, mientras que para el minimalismo deben utilizarse estrictamente los argumentos que definan el problema planteado (GROSMAN: 2010). Los enfoques minimalistas o maximalista influyen no solamente en la forma como el juez redacta su sentencia sino cómo se identifican los precedentes vinculantes, es decir, como se identifica la ratio decidendi de una sentencia. Sobre este último aspecto, debe decirse que mientras para los minimalistas debe prestarse particular atención a los hechos relevantes de los casos (material facts) para los maximalistas deben atenderse reglas generales en cuyo supuesto los hechos relevantes de la sentencia son solo una de sus propiedades.

Los argumentos que definen los enfoques minimalista y maximalista son de índole pragmáticos y normativos. Pragmáticamente los maximalistas defienden que, como forma para la toma de decisiones, el minimalismo reduce los costos de la decisión y los costos de error. Normativamente, el minimalismo es sensible a la práctica democrática toda vez que se dejan abiertos asuntos generales y sustanciales mientras son definidos por instituciones democráticas. Igualmente, al dejar abiertas cuestiones sustanciales, se respeta a las personas que estén en desacuerdo con tales materias. En oposición, los maximalistas defienden que las reglas minimalistas incrementan los costos de 
error de las decisiones de futuros jueces al no establecer criterios generales que limiten realmente las decisiones posteriores. Asimismo, sentar reglas generales puede potenciar la práctica democrática en la medida que se define lo que los órganos democráticos pueden o no pueden hacer. (CAJAS, 2008 y SUNSTEIN: 2001 y 2008).

Una distinción adicional entre minimalistas y maximalistas es el método de aplicación del precedente. Para los maximalistas el precedente se aplica por medio de argumentos analógicos. Si en la sentencia 1 se decidió el caso conformado por las propiedades $\mathrm{A}, \mathrm{B}$ y $\mathrm{C}$ según la solución $\mathrm{X}$, en la sentencia 2 se debe dar la solución X si y solo si las propiedades son similares a la sentencia 1 . Por el contrario, para los maximalistas los precedentes $e$ aplican deductivamente median te un razonamiento silogístico. (MAGALOINI: 2001).

En un amplio estudio sobre el control judicial de las reformas constitucionales en Colombia, M. Cajas Sarria (2010) explica como la Corte Constitucional recurrió a la metodología minimalista en la sentencia C-816-2004 (magistrados ponentes Jaime Córdova Triviño y Rodrigo Uprimny Yepez). De acuerdo con el análisis de dicho autor, la Corte prefirió estudiar minuciosamente los vicios de tramite en una reforma constitucional (específicamente en el trámite del acto legislativo 02 de 2003) en lugar de resolver acerca de una posible sustitución de la constitución ${ }^{12}$. De esta manera, el enfoque minimalista de

12 La teoría de la sustitución de la Constitución fue patentada en la sentencia C-551 de 2003 (Magistrado ponente Eduardo Montealegre Lynett) y pretende establecer límites materiales a la reforma constitucional. En pocas palabras la teoría formula que la Constitución otorgó a los órganos competentes para reformar la Constitución (el Congreso, el Pueblo y la Asamblea Constituyente) la facultad de reformar la constitución más no de sustituirla. Para identificar si un acto es una sustitución se debe establecer que transforma un elemento esencial de la Constitución sustituyéndolo por otro. Sin embargo, en el juicio de sustitución de la Constitución resulta altamente indeterminado identificar aquellos elementos que hacen parte de la esencia de la Constitución debiendo recurrirse a complejas discusiones morales. (véase Juan Carlos Lancheros \& Fabio Pulido Ortiz, 2010.) la Corte Constitucional dejo abierta la discusión sobre el dilema político de fondo planteado en el acto legislativo 02 de 2003 (la constitucionalidad el estatuto antiterrorista). En el análisis se concluye que la Corte recurrió a la metodología minimalista en virtud de la "carencia de acuerdo sobre el tema" y el escaso consenso acerca de lo que significa la sustitución de la Constitución. En otro trabajo, el mismo autor defendió que "en el caso del estatuto antiterrorista, cuya inconstitucionalidad fue resuelta en la sentencia C-816 de 2004, resulta cómodo defender la postura minimalista de la Corte Constitucional, pues la decisión evitó poner en riesgo los derechos fundamentales" (CAJAS: 2008: 77).

Existe, en todo caso, la tendencia a definir el precedente de las sentencias " $\mathrm{C}$ " de una forma maximalista y las sentencias tipo "T" de una forma minimalista. En la sentencia C-083-1995, para explicar la fuerza vinculante de las sentencias de la Corte Constitucional, se dijo que las normas constitucionales no se pueden aplicar directamente y requieren de la subregla elaborada por la Corte Constitucional, es decir una norma que precisa el texto constitucional. En ese sentido, se define la tarea de la Corte -en su condición de intérprete autorizado de la Constitución- como la competencia para crear normas constitucionales, las cuales deberán ser aplicadas deductivamente pro el resto de los jueces del país.

Por el contrario, sobre las sentencias de tutela, desde la sentencia C-037-1996 se ha dicho que "sirven como criterio auxiliar de la actividad de los jueces, pero si éstos deciden apartarse de la línea jurisprudencial trazada en ellas, deberán justificar de manera suficiente y adecuada el motivo que les lleva a hacerlo, so pena de infringir el principio de igualdad". De este modo, el sistema de precedentes, referido específicamente a las decisiones de tutela emitidas por la Corte Constitucional, debe entenderse de manera tal que el efecto inter-partes de las sentencias de tutela se limite en exclusiva a la resolución concreta del caso, mientras que la razón constitucional en la que se fundamentó el resultado tiene fuerza gravitacional respecto de los demás casos que 
sean planteados y que sean fácticamente similares al ya decidido por la Corte ${ }^{13}$. Así, el juez debe seguir el precedente constitucional, salvo en caso de que pueda justificar el tratamiento diferencial que pretende otorgar. De lo contrario, si no verifica el precedente constitucional con fuerza gravitacional y no manifiesta las razones del cambio, el juez viola la igualdad de trato prescrita por el Art. 13 de la Constitución Política ${ }^{14}$.

Esta doctrina fue amplia en la sentencia C-8362001 en la cual se definió que en el sistema jurídico colombiano existe un sistema flexible de precedentes, en virtud del cual los jueces, si bien tienen el deber prima facie de respetar el precedente propio (horizontal) y el de los órganos de cierre (vertical), pueden también apartarse de esas decisiones judiciales. Es así como se han considerado como argumentos legítimos para apartarse del precedente: ${ }^{15}$

(i) Distinciones de hecho: todo precedente debe ser respetado a menos que pueda ser distinguido, es decir, que se encuentren razones para realizar una distinción relevante entre las circunstancias del caso precedente y el que está por decidirse. En otras palabras, los precedentes son obligatorios siempre que los casos en curso sean análogos a los previamente fallados.

(ii) Distinción entre ratio decidendi y obiter dictum: Los sistemas jurídicos de tradición anglosajona se han diferenciado dos partes principales en el cuerpo argumentativo de las sentencias: la ratio decidendi y el obiter dictum. En estricto sentido, los jueces no están obligados a seguir las sentencias antecedentes sino la ratio decidendi de las mismas.

13 Sobre el concepto de fuerza gravitacional, véase $\mathrm{R}$. Dworkin (1984, p. 184-185).

14 Véase entre otras las sentencias C-037-1996 (Magistrado ponente Alvaro Taf ur Galvis )C-836-2001 (Magistrado ponente Rodrigo Escobar Gil) y la sentencia T-292-2006 (Magistrado Ponente Manuel José Cepeda)

15 Véase la sentencia C-836-2001. Doctrinalmente véase D. López (2006) y C. Bernal (2005). (iii) Modificación del precedente ${ }^{16}$. La Corte Constitucional, en la sentencia C-836 de 2001, definió que los jueces pueden separarse de la jurisprudencia de las altas Cortes siempre que: (1) exista un cambio en el material jurídico relevante que motive el cambio de jurisprudencia; (2) medie un cambio en la situación social, política o económica, que tenga relación directa con la forma como se había formulado el principio jurídico, y que esté razonablemente justificado conforme a una correcta ponderación de los bienes jurídicos comprometidos en el respectivo caso, y (3) la jurisprudencia sea contradictoria o imprecisa, caso en el cual los jueces deben hacer explícita la diversidad de criterios ${ }^{17}$. Las altas Cortes, además, pueden cambiar de jurisprudencia cuando consideren que existe una jurisprudencia errónea, aunque no medie un cambo legislativo, político, social o económico determinante, siempre y cuando se argumente explícitamente por qué se considera que el nuevo precedente es superior jurídica y moralmente al anterior.

Entones, según los argumentos expuestos, los precedentes " $C$ " son maximalistas mientras que los "T" minimalistas. En la sentencia

16 Las distinciones fácticas y la distinción entre ratio decidendi y obiter dicta, no son, en estricto sentido, argumentos que justifiquen no seguir un precedente, sino, argumentos que formulan su no aplicabilidad; es decir, están destinados a señalar distinciones en torno a asuntos fácticos o de derecho, con objeto de demostrar que determinado precedente no es aplicable al caso a decidir

17 Esta doctrina es un "préstamo" de la Corte Constitucional colombiana de similar a la establecida por la Corte Suprema de los Estados Unidos en el caso Patterson vs. Malean Credit Union (491 U.S. 164 1998). En esa oportunidad, el juez Kennedy elaboró una lista de argumentos para no seguir un precedente, en la que justificó tal proceder, entre otras razones, cuando la intervención de cambios en el derecho hagan el precedente anacrónico u obsoleto; cuando se muestre que el precedente afecta la coherencia o consistencia del derecho, y cuando se muestre que el precedente es inconsistente con el sentido contemporáneo de justicia o de bienestar social (lista citada en D. Shapiro, 2008) 
T-292-2006, se reiteró la diferencia entre el precedente tipo " $\mathrm{C}$ " y el tipo "T". En esta decisión se expusieron algunos criterios para identificar la ratio decidendi de las sentencias:

(i) Constituye en sí misma una regla suficientemente clara, que permite resolver efectivamente si la norma juzgada se ajusta o no a la Constitución. Como regla, implica una autorización (facultad), una prohibición o una orden (obligación) derivada de la Constitución

(ii) La ratio decidendi generalmente responde al problema jurídico que se plantea en el caso, y se enuncia como una regla jurisprudencial que fija el sentido de la norma constitucional, en la cual se basó la Corte para abordar dicho problema jurídico.

(iii) Deben tenerse en cuenta las sentencias posteriores, sobre el mismo asunto, proferidas por la Corte. La ratio decidendi puede consolidarse en una oportunidad posterior cuando de manera reiterada se reafirma la regla.

(iv) Sobre la ratio decidendi en materia de tutela, se argumentó que está limitada por el principio de igualdad, en el sentido de que son les hechos relevantes del caso los determinantes para identificar el precedente.

Ahora bien, ¿Por qué aplicar el enfoque maximalista a las sentencias tipo "C" y el minimalista a las sentencias tipo "T"? La respuesta a esta cuestión obedece las problemáticas identificadas en la primera parte de éste artículo. Si las sentencias "C" no tienen caso, su ratio decidendi será "abstracta", "general". Como las sentencias "T" son casos, su ratio decidendi está ligada a ellos. Sin embargo como se concluyó en la primera parte, la diferencia en los procesos constitucionales no es la existencia o inexistencia de casos. Tanto las sentencias " $C$ " como las "T" resuelven asuntos en los cuales se involucran hechos y los diferentes grados de generalidad o particularidad no dependen del tipo de sentencia si no de la estrategia argumentativa del juez, quien define el nivel de generalidad del caso. La dificultad teórica de definir como maximalistas los precedentes "C" y como minimalistas los " $T$ ", llevo a que la Corte, en la sentencia T-292-2006, a matizar tal distinción. Se expuso que para identificar precedentes, que en la ratio decidendi de la sentencia se encuentra una regla relacionada con el caso a resolver posteriormente. $\mathrm{Y}$ se agregó que "los hechos del caso o las normas juzgadas en la sentencia anterior deben ser semejantes o plantear un punto de derecho semejante al que debe resolverse posteriormente" y que "en este sentido será razonable que "cuando en una situación similar, se observe que los hechos determinantes no concuerdan con el supuesto de hecho, el juez esté legitimado para no considerar vinculante el precedente. Con estas últimas ideas parece afirmarse que los precedentes, tanto " $\mathrm{C}$ " como sentencias " $T$ ", se identifican y aplican a través de argumentos analógicos.

\section{CONCLUSIONES}

Las características del control constitucional que realiza la Corte Constitucional Colombiana no pueden ser explicada según la tradicional distinción entre control abstracto y concreto. El carácter multifacético del rol de dicha Corte evidencia diferentes variables y matices que deben ser estudiados para comprender el Control Constitucional. Por ejemplo, resulta de especial relevancia para los estudios político-constitucionales investigar con mayor detenimiento la incidencia de factores extrajurídicos en el desarrollo de la actividad de la Corte, por ejemplo, los cambios en su composición o la influencia de momentos políticos, sociales y económicos.

De esta manera, para comprender el control constitucional, debe prestarse mayor atención al hecho de que la definición de las normas involucradas es un asunto valorativo y manipulable. Los hechos y textos, objeto del control, no son más que el material que utiliza el juez para componer el juicio de constitucionalidad. Por ello, las propiedades que conforman las variables del control pueden llegar a ser tan variadas que los conflictos constitucionales no 
pueden ser definidos a priori y dependen de las particularidades de cada juicio. No se defiende una homogeneización de todos los asuntos, sino que las particularidades de los casos que se presentan son de tan variados matices que las clasificaciones son por lo menos inútiles.

De la conceptualización de los enfoques maximalista y minimalista surgen preguntas valorativas, metodológicas y empíricas del precedente constitucional en Colombia. Asuntos de tipo valorativo como ¿Qué tipo de enfoque debe utilizar la Corte para resolver los casos? Metodológicos como ¿Cual enfoque se debe usar para identificar el precedente constitucional? y empíricos como ¿Es la Corte maximalista o minimalista? Y ¿La teoría del precedente constitucional desarrollada por la Corte es maximalista o minimalista?

En todo caso, la tendencia de aplicar el enfoque maximalista a las sentencias tipo " $\mathrm{C}$ " y el minimalista a las sentencias tipo " $\mathrm{T}$, se sustenta en los equívocos generados en las clasificación del control constitucional entre abstracto y concreto. Por las características involucradas en los juicios de constitucionalidad se debe concluir que no es posible ir muy lejos en las consecuencias jurídicas del precedente. Sobre este particular, se debe tener en cuenta que en la sentencia C-3552008 en la que se estableció confusamente que para establecer si un funcionario público, incurrió en prevaricato, "resultará indicativo examinar si se está en presencia de un alejamiento del de una sub-regla constitucional constante" como en el caso de los fallos de reiteración en los que "la Corte (i) simplemente se limita a reafirmar la vigencia de una subregla constitucional perfectamente consolidada; (ii) su número resulta ser extremadamente elevado; $y$ (iii) constituyen interpretaciones constantes y uniformes de la Constitución, la ley o un acto administrativo de carácter general, por parte del juez constitucional" Tal conclusión (derivar consecuencias penales del desconocimiento de precedentes) es desproporcionada, cuando no existe enfoque analítico o metodológico para definir la norma jurídica vinculante involucrada en una providencia judicial.
Debe tenerse en cuenta además que existen serias dificultades teóricas para limitar a la Corte Constitucional en la conformación de los casos. Debe tenerse en cuenta que los casos que resuelve la Corte pueden ser reales o hipotéticos. Son ralaes aquellos casos en los que sus propiedades se refieren a situaciones que existieron o existen. A su vez son hipotéticos los casos en los que las propiedades están conformadas por supuestos que se espera que ocurran. En las sentencias en las que se juzgan casos reales, es decir las sentencias " $T$ " y las " $C$ " que juzgan vicios en la formación de las leyes y actos reformatorios de la Constitución, la Corte cuenta con un alto grado de discrecionalidad al definir los hechos que conforman el caso. Existe, sin embargo, una diferencia relevante que determina una mayor discrecionalidad de la Corte Constitucional en la definición del caso en las sentencias "C" que juzgan vicios en la formación de las leyes y actos reformatorios de la Constitución: no existen instancias judiciales que delimiten el caso previo a la llegada del mismo a la Corte Constitucional como si ocurre en los procesos de tutela. Los problemas para limitar la conformación del caso son mucho mayores en las sentencias "C" que resuelven cuestiones de fondo pues la conformación de este es esencialmente argumentativa en el sentido de que será la interpretación que de la Corte de la ley enjuiciada la que defina las propiedades que conforman el caso.

Por último debe estudiarse la conveniencia de concebir jurídicamente a las sentencias de la Corte Constitucional, dado el carácter eminentemente político del control constitucional de las leyes. De esta manera, incorporar conceptos importados de tradiciones jurídicas del common law (i.e la teoría del precedente) resulta problemática dadas laca características institucionalmente diferentes entre, por ejemplo, la Suprema Corte estadounidense y la Corte Constitucional colombiana. En esta misma línea debe discutirse acerca de las implicancias del hecho de que un mismo órgano del estado sea el "director" de la política constitucional y que, a su vez, defina su aplicación a casos concretos. 


\section{BIBLIOGRAFÍA}

\section{Libros y revistas}

Alchourron, C. y Buligyn, E. (1974) Introducción a la Metodología de las Ciencias Jurídicas y Sociales. Buenos Aires: Astrea

Aguilo, J. (2000). Las Fuentes del Derecho. Barcelona: Ariel.

Atienza, M y Ruiz Manero, J. (1996) Las piezas del derecho: teoría de los enunciados jurídicos. Barcelona: Ariel.

Bernal Pulido, C. (2005). El Derecho de los Derechos. Bogotá: Universidad Externado de Colombia.

Cajas Sarria, M. (2008) El control judicial a la reforma constitucional: Colombia 1910-2007. Cali: ICESI.

Cajas Sarria, M. (2010). Minimalismo judicial ¿Cass Sunstein en la Corte Constitucional?. Revista Precedente, 57-81.

Carrio, G. (1978). Notas sobre derecho y lenguaje. Buenos Aires: Abeledo-Perrot.

Cueto Rua, J. (1997). El Common Law. Buenos Aires: Abeledo-Perrot.

Dworkin, R. (1984). Los Derechos en Serio. Barcelona: Ariel.

García de Enterría, E. (1983). La Constitución como norma y el Tribunal Constitucional. Madrid: Civitas.

Ferreres Comella, V. (2005). Las consecuencias de centralizar el control de constitucionalidad de la ley en un tribunal especial. En Saba, R. (Ed). Los límites a la democracia. Buenos Aires: Editores del Puerto.

Frank, J. (1949). Courts on Trial: myth and reality in American justice. Princeton: Princeton University Press.

Goodhart, A. L. (1930). Determining the Ratio Decidendi of a Case". Yale Law Journal 40 (2), 161-183.

Grosman, L. (2010). "El caso Arriola o las penurias del maximalismo". En Suplemento
Extraordinario Constitucional 75 Aniversario de La Ley, 53-76.

Guastini, R. (1999). Distinguiendo. Barcelona: Gedisa.

Guastini, R. (2008). Teoría e ideología de la interpretación constitucional. Madrid: Trotta.

Iturralde Sesma, V. (1995). El Precedente en el Common Law. Madrid: Civitas.

Kališe R., Is the English Doctrine of Judicial Precedent, Becoming Only an Illusion?, KALIŠ, Roman.? (2008) Česká republika:

Masarykova univerzita. Disponible en www.law. muni.cz/edicni/dp08/files/pdf/SBORNIK.pdf

Kelsen, H. (1991). Teoría pura del Derecho. Mexico: Porrúa-UNAM.

Kelsen, H. "Judicial Review of Legislation. A Comparative study of the Austrian and American Constitution. The Journal of Politics 4 (2), 183-200.

Kennedy, D. (1999). Libertad y Restricción en la Decisión Judicial. Bogotá: Siglo del Hombre editores.

Lancheros Gámez, J. (2010). El Precedente Constitucional en Colombia y su Estructura Argumentativa. Disponible en http://www. derechojusto.org/images/stories/precedente_ judicial/el_precedente_constitucional_en colombia y su estructura argumentativa.pdf. Visitada el 1 de octubre de 2010.

Legarre, S y Rivera J. (2006). Naturaleza y Dimensiones del Stare Decisis. Revista chilena Derecho 33 (1), 109-124.

López Medina, D. (2006). El Derecho de los Jueces. Bogotá: Legis.

Lucke, HK, (1989). "Ratio decidendi: adjudicative rationale and source of law". Bond Law Review, 1 (1), 36-51.

Merryman J.. (1989). La Tradición Jurídica Romano - Canónica. México: Fondo de Cultura Económica.

Magaloni,A. (2001).ELprecedenteconstitucional en el sistema judicial norteamericano. Madrid: Mc Graw Hill. 
Moreso, J. (1998). La indeterminación del derecho y la interpretación constitucional",. Madrid: Centro de Estudios Constitucionales.

Nino, C. (1980). Introducción al Análisis de Derecho. Buenos Aires: Astresa.

Nino, Carlos Santiago. (1992). Fundamentos de Derecho Constitucional. Buenos Aires: Astrea.

Pulido Ortiz, F. (2011). Informe parcial "doctrina judicial de la Corte Constitucional: 20 años de jurisprudencia", Universidad Católica de Colombia y Fundación Derecho Justo, mayo de 2010

Pulido Ortiz, F. (2010a). Las sentencias de Humberto Sierra porto en procedimiento legislativo y los cambios en la conformación de la corte constitucional colombiana, Novum Ius, 2010, 4 (1), 183-206.

Pulido Ortiz, F. (2010b). Indeterminación del Derecho y la Sentencia C-083-1995, Fundación Derecho Justo, 2010, disponible en http://www.derechojusto. org/images/stories/Publicaciones/indeterminacion del_derecho_y_la_sentencia_c-083-1995.pdf. Visitada el 1 de octubre de 2010

Pulido Ortiz, F. (2009a). Informe final de investigación "elementos jurisprudenciales de los magistrados Humberto Sierra Porto, Mauricio González Cuervo y Nilson Pinilla Pinilla", Universidad Católica de Colombia, diciembre de 2009

Pulido Ortiz, F. (2009b) "la coherencia del derecho en la relación entre la Corte Constitucional y la Sala Laboral de la Corte Suprema de Justicia", Tesis de Maestria inedita, Universidad de Palermo, Argentina.

Pulido Ortiz, F. (2008). Elementos relevantes para el análisis de las sentencias de la Corte Constitucional. Novum Jus 2 (1). 125-152.

Rincón, R. y Suarez, I. (2010). La jurisprudencia constitucional como marco normativo del trámite legislativo ordinario. En Escenarios Socio Juridicos. Disponible en http://www. redsociojuridica.org/escenarios/jurisprudencia marco_normativo_tramite_legislativo_ordinario. htm (visitada el 1 de marzo de 2011).
Quinche, M. (2008). Derecho Constitucional Colombiano: de la Carta de 1991 y sus reformas. Bogotá: Grupo Editorial Ibáñez.

Shapiro, D. (2008). The role of precedent in constitutional adjudication: an introspection. Texas Law Review, 86 (5), 929-956

Sodero E. (2004). Sobre el Cambio de los Precedentes. Isonomía: Revista de teoría y filosofía del derecho, 21 (1), 217-254.

Sunstein, C. (2008). Beyond Judicial Minimalism, Harvard Public Law Working Paper No. 08-40; U of Chicago, Public Law Working Paper No. 237; U of Chicago Law \& Economics, Olin Working Paper No. 432; Harvard Law School Program on Risk Regulation Research Paper No. 08-6. Available at SSRN: http://ssrn.com/abstract $=1274200$.

C. Sunstein. (2001). One case at a time: judicial minimalism on the Supreme Court. Cambridge: Harvard University Press.

Fon, Vy Parisi, F. (2006) Judicial Precedents in Civil Law Systems: A Dynamic Analysis.. International Review of Law and Economics, Forthcoming, 26 (1). Available at SSRN: http://ssrn.com/ abstract $=534504$ or doi:10.2139/ssrn.534504.

Waldron J. (1999). The Dignity of Legislation. Cambridge: Cambridge University Press.

\section{Providencias}

Corte Constitutional

T-406-1992

C-083-1995

C-037-1996

C-836-2001

T-292-2006

T-856-2007

C-355-2008

Corte Suprema de los Estados Unidos

Caso Patterson vs. Malean Credit Union (491 U.S. 164 1998) 